\title{
Postoperative swallowing disorder after thyroid and parathyroid resection
}

\section{Andreas Hillenbrand Gregor Cammerer Lisa Dankesreiter Johannes Lemke Doris Henne-Bruns}

Department of General and Visceral Surgery, Ulm University Medical Center, 8908I Ulm, Germany
Correspondence: Andreas Hillenbrand Department of General and Visceral Surgery, Ulm University Medical Center, Albert-Einstein-Allee 23, 8908I Ulm, Germany

Tel +4973I500536II

Fax +4973I50053503

Email Andreas.Hillenbrand@uniklinikulm.de
This article was published in the following Dove Press journal: Pragmatic and Observational Research

Introduction: Dysphagia is frequently reported after thyroidectomy. Here, we investigated the incidence of postoperative dysphagia after uncomplicated thyroidectomy and parathyroidectomy. Further, we analyzed diagnosis and types of therapy to identify possible patients at risk.

Patients and methods: A questionnaire was sent to 372 consecutive patients whose thyroid or parathyroid glands were operated on between May 2013 and October 2014 at Ulm University Hospital. Patients were questioned at least 6 months postoperatively.

Results: In the evaluation, 219 questionnaires could be included. Fifty-three (21.3\%) patients reported that the overall postoperative swallowing process was better or more trouble-free. In 110 (50.2\%) patients, dysphagia was reported only immediately postoperative and disappeared later spontaneously. Sixteen patients (7.3\%) stated that after a maximum of 3 months after surgery they suffered from dysphagia. One $(0.5 \%)$ patient stated that up to 3 months postoperatively, swallowing problems had been successfully treated by logopedic therapy. In 39 (17.6\%) patients, the complaints persisted for more than 3 months or still existed at the time of the interview. We found no correlation between dysphagia and patients' age or gender, the specimen volume, and patients' body mass index. The more invasive the operation was, the more patients suffered from dysphagia. Analyzing the frequency of dysphagia according to different diagnoses, we found a significant risk of postoperative dysphagia in patients with Graves' disease and carcinoma. Patients operated on for hyperparathyroidism were at significantly decreased risk of dysphagia. Conclusion: Nearly $20 \%$ of patients reported postoperative dysphagia after uncomplicated thyroidectomy and parathyroidectomy, especially after major surgical intervention. We found a significant risk of postoperative dysphagia in patients with Graves' disease and carcinoma and a decreased risk for patients operated on for hyperparathyroidism.

Keywords: dysphagia, thyroidectomy, parathyroidectomy

\section{Introduction}

Dysphagia is a typical symptom complained of preoperatively by patients with enlarged thyroid due to a direct compression of the swallowing organs. ${ }^{1}$ In these patients, uncomplicated thyroidectomy often leads to improvements in perceptions of swallowing function. ${ }^{2}$ But impaired swallowing and neck strangling also occur postoperatively. Impaired swallowing and neck strangling following uncomplicated operative thyroid or parathyroid resection are frequently complained of by patients. ${ }^{3,4}$ Intraoperative nerve injury regularly causes postoperative dysphagia, but dysphagia is also complained of after uncomplicated thyroidectomies. ${ }^{2,5}$ These symptoms are usually dismissed by the clinicians or attributed to orotracheal intubation. ${ }^{6}$ In many patients, correlations 
for these swallowing disorders cannot be found in objective test results. ${ }^{6}$ Reasons for dysphagia and esophageal motility changes after uncomplicated thyroidectomy could be lesions of the perithyroidal neural plexus, changes in the laryngeal vascular supply, postoperative adhesions, decreased pressure of the upper esophageal sphincter, or changed position after thyroidectomy. ${ }^{5}$ Here, we investigated the incidence of postoperative dysphagia after uncomplicated thyroidectomy and parathyroidectomy. Further, we analyzed diagnosis and types of therapy to identify possible patients at risk.

\section{Patients and methods}

In this retrospective cohort study, we sent questionnaires to 372 consecutive patients whose thyroid or parathyroid glands were operated on between May 2013 and October 2014 at Ulm University Hospital. Excluded from the evaluation were 27 patients with preoperatively existing $(n=10)$ or postoperative $(n=17)$ temporary or permanent paralysis of the recurrent nerve, since swallowing complaints and vocal changes are to be expected in these patients. ${ }^{2}$ Patients were questioned between 6 and 18 months postoperatively (median 14 months). The questionnaire was sent at least 6 months postoperatively, since mild symptoms may occur in most patients within the first 3 months. ${ }^{6}$ The patients' age, body mass index, diagnosis, and type of operation were analyzed from patients' records. The volume of the resected tissue was analyzed from the length/width/height data provided by the pathology report (longitudinal diameter of the lobextransverse diameter $\times$ lobe thickness). The nicotine consumption and the subjective postoperative swallowing changes were examined via a questionnaire (Table 1). All patients were examined pre- and postoperatively by an ear, nose, and throat physician. Recurrent laryngeal nerve injury was diagnosed by means of laryngoscopic examination. Vocal cord paralysis that resolved within 6 months of surgery was considered transient; those that did not resolve in 6 months were classified as permanent. Written informed consent was obtained from all participating patients. The study was approved by the ethical committee of the University of Ulm (Nr 141/15).

\section{Surgical technique}

All patients underwent conventional surgery. Parathyroid surgery was performed without a routine four-gland exploration. Vagal nerve and inferior laryngeal nerve were identified systematically with intermittent nerve monitoring. The external branch of the superior laryngeal nerve is not exposed routinely. All surgical procedures were performed or supervised by an experienced endocrine surgeon. Routine laryngoscopic examination was performed by an ear, nose, and throat specialist before and after surgery.

\section{Statistical analysis}

Descriptive statistics were used to summarize demographic and clinicopathologic characteristics. Correlation of dysphagia with patients' age, the specimen volume, and patients' body mass index was calculated with Spearman's rank correlation coefficient. The influence of the different therapy method or different diagnosis on dysphagia risk was examined by the chi-squared test. For this, the option 'therapy $\mathrm{X}$ ' vs 'non-therapy X' (X stands for total thyroidectomy [TT], hemithyroidectomy, TT with LK, etc.) or 'diagnosis X' vs 'non-diagnosis $\mathrm{X}$ ' (X stands for benign struma, hyperparathyroidism, malignancy, and Graves' disease) were compared. The null hypothesis was formulated that no dependence of the frequency of the complaints of the therapy $\mathrm{X}$ or diagnosis $\mathrm{X}$ exists. All tests of significance were at the $P<0.05$ level.

Table I Questionnaire sent to 358 patients at least 6 months postoperatively

\section{Which of the 5 answers is closest, please tick only one answer}

\begin{tabular}{|c|c|c|c|c|c|c|}
\hline$\square$ & \multicolumn{6}{|c|}{ a) After the removal of the thyroid, the swallowing process is improved overall / trouble-free, since no more items are troublesome. } \\
\hline$\square$ & \multicolumn{6}{|c|}{ b) I had swallowing difficulties immediately after the operation (about a week), which disappeared by themselves. } \\
\hline$\square$ & \multicolumn{6}{|c|}{$\begin{array}{l}\text { c) I had swallowing difficulties during the first weeks postoperatively (maximum } 3 \text { months after surgery), which disappeared without further } \\
\text { treatment. }\end{array}$} \\
\hline$\square$ & \multicolumn{6}{|c|}{$\begin{array}{l}\text { d) I had swallowing difficulties during the first weeks postoperatively (a maximum of } 3 \text { months after surgery), which required treatment by } \\
\text { means of: }\end{array}$} \\
\hline \multirow[t]{7}{*}{$\square$} & \multirow{2}{*}{\multicolumn{6}{|c|}{$\begin{array}{l}\text { e) I have long-lasting / still existing difficulty swallowing. } \\
\text { (if you have ticked e), please fill in the following field) }\end{array}$}} \\
\hline & & & & & & \\
\hline & & Never & Rare & Frequent & Always & Comment \\
\hline & I must cough, and I have swallowing problems & $\square$ & $\square$ & $\square$ & $\square$ & \\
\hline & I feel discomfort swallowing & $\square$ & $\square$ & $\square$ & $\square$ & \\
\hline & I find it difficult to swallow meat/bread/tablets & $\square$ & $\square$ & $\square$ & $\square$ & \\
\hline & I had the sensation of a lump or tightness in my throat & $\square$ & $\square$ & $\square$ & $\square$ & \\
\hline
\end{tabular}




\section{Results}

Of 372 questionnaires, 222 were returned. In the evaluation, 219 returns could be included. The group of patients who did not respond to the questionnaire did not differ significantly from the 219 included patients in terms of age, sex, proportion with cancer, or mass of resected thyroid. Demographic-, disease-, and treatment-related variables for the study cohort are summarized in Table 2 .

\section{Swallowing}

Fifty-three (21.3\%) patients reported that the overall postoperative swallowing process was better or more trouble-free (answer a; Table 1). In 110 (50.2\%) patients, the symptoms were only immediately postoperative and later disappeared spontaneously (answer b). Sixteen patients (7.3\%) stated that at a maximum of 3 months after surgery they suffered from dysphagia (answer c). One $(0.5 \%)$ patient stated that up to 3 months postoperatively, swallowing problems had been successfully treated by logopedic therapy (answer d). In $39(17.6 \%)$ patients, the complaints persisted for more than 3 months or still existed at the time of the interview (answer e) (Figure 2).

We found no correlation between dysphagia and patients' age, the specimen volume, and patients' body mass index (Spearman's rank correlation coefficient $=-0.1$, each). Further, there was no dependency of dysphagia on gender. In

Table 2 Demographic-, disease-, and treatment-related variables for the study cohort

\begin{tabular}{|c|c|c|}
\hline & & $n=219$ \\
\hline Age (median; range) & Years & $58(17-86)$ \\
\hline \multirow[t]{2}{*}{ Gender (n [\%]) } & Female & $160(73.1 \%)$ \\
\hline & Male & 59 (26.9\%) \\
\hline BMI (median; range) & $\mathrm{kg} / \mathrm{m}^{2}$ & $26.1(15.8-46.4)$ \\
\hline $\begin{array}{l}\text { Specimen volume } \\
\text { (median; range) }\end{array}$ & $\mathrm{cm}^{3}$ & $48.0(0.1-2160)$ \\
\hline \multirow[t]{4}{*}{ Diagnosis (n [\%]) } & Struma & I 52 (69.4\%) \\
\hline & Hyperparathyroidism & 35 (I6.0\%) \\
\hline & Malignancy & $23(10.5 \%)$ \\
\hline & Graves' disease & $9(4.1 \%)$ \\
\hline \multirow[t]{6}{*}{ Surgery (n [\%]) } & $\begin{array}{l}\text { Thyroidectomy with central } \\
\text { and lateral neck dissection }\end{array}$ & $6(2.7 \%)$ \\
\hline & $\begin{array}{l}\text { Thyroidectomy with central } \\
\text { neck dissection }\end{array}$ & $12(5.5 \%)$ \\
\hline & Total thyroidectomy & 71 (32.4 \%) \\
\hline & Dunhill operation & 13 (5.9\%) \\
\hline & Thyroid lobectomy ${ }^{\mathrm{a}}$ & $84(38.4 \%)$ \\
\hline & Parathyroidectomy & 33 (15.1 \%) \\
\hline \multirow[t]{2}{*}{ Smoking ${ }^{\mathrm{b}}(\mathrm{n} /[\%])$} & Yes & 24 (I I.5 \%) \\
\hline & No & 194 (88.5\%) \\
\hline
\end{tabular}

Notes: ancluded two patients with parathyroidectomy. 'ंOne patient failed to complete the smoking field. the group of smokers, 5 out of $24(20.8 \%)$ patients reported dysphagia and 34 out of 194 (17.5\%) non-smokers patients reported dysphagia (no significant difference; chi-squared test $=0.2$ ).

\section{Extent of operation}

The more invasive the operation was, the more patients suffered from dysphagia. Depending on the operation, dysphagia occurred between $6.1 \%$ for parathyroid resection and $33 \%$ for TT with lymph node dissection (Figure 1). Frequency of swallowing disorder was similar in patients with sixth level dissection and patients with additionally lateral neck dissection (lateral neck dissection: 2 out of 6; sixth level dissection: 4 out of 12 patients).

We tested the hypothesis (dependence of the frequency of the complaints of the therapy $\mathrm{X}$ or diagnosis $\mathrm{X}$ ) with the chi-squared test. The chi-squared test showed no significant relation between operation and dysphagia (thyroidectomy with/without lymph nodes: chi-squared test=3.2/2.7, subtotal

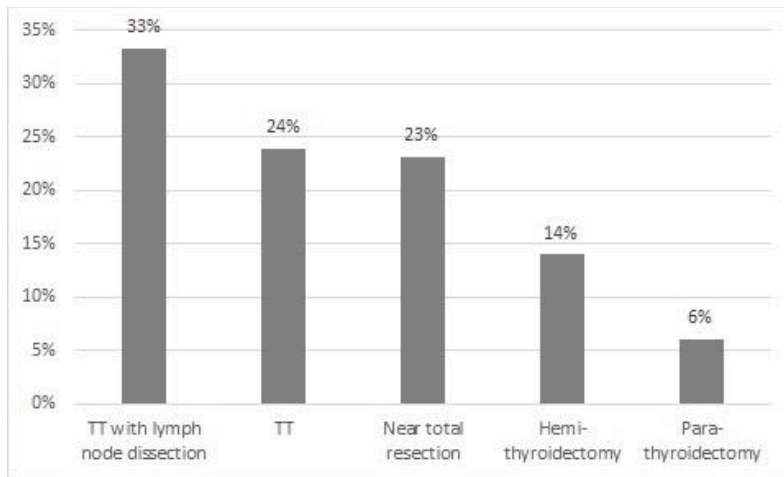

Figure I Frequency and duration of postoperative dysphagia complaints Abbreviation: TT, total thyroidectomy.

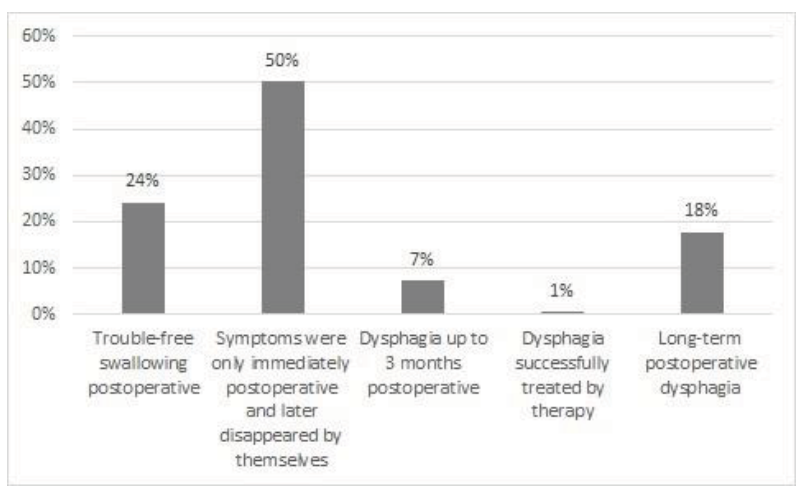

Figure 2 Frequency of dysphagia depending on the operative therapy. Notes: The more invasive the operation was, the more patients suffered from dysphagia. Dysphagia occurred depending on the operative therapy between $6.1 \%$ for parathyroid resection and 33\% for total thyroidectomy with lymph node dissection. 
resection/hemithyroidectomy: chi-squared test $0.3 / 2.1$, and parathyroid resection: chi-squared test=3.7). Analyzing the frequency of dysphagia according to different diagnoses, we found a significant risk of postoperative dysphagia in patients with Graves' disease (chi-squared test=4.6) and carcinoma (chi-squared test=8.0). Further, patients operated on for hyperparathyroidism were at significantly decreased risk of dysphagia (chi-squared test=4.2; Figure 3).

\section{Discussion}

The results of this study confirm that patients frequently experience postoperative swallowing changes, even after uncomplicated surgery in the absence of laryngeal nerve injuries. In the early postoperative weeks after thyroidectomy, swallowing impairment is self-explanatory and is reported by most patients. ${ }^{6}$ Symptoms are often self-limiting, are not related to impaired nerve function and improve spontaneously. Most of the symptoms resolved within 3 months of operation, but we found longer lasting dysphagia in almost $20 \%$ of patients. Most patients complaining of long term swallowing disorders had bilateral thyroid resection with or without lymph node dissection. Patients operated on for hyperparathyroidism were at significantly decreased risk of dysphagia. However the number of parathyroidectomy surgeries is very small (only 33 patients) and results can be influenced by the small number. Further, minimally invasive parathyroidectomy is safe and rapid, the dissection is very minimal for the patients unlike other techniques.

Our results are in line with two other studies, which also reported postoperative swallowing impairment in about $20 \%$ of patients after thyroidectomy, and where patients with carcinoma were excluded in both studies ${ }^{5-7}$ Compared with preoperative symptoms, Scerrino et al reported that dysphagia improves in the majority of patients after operative therapy,

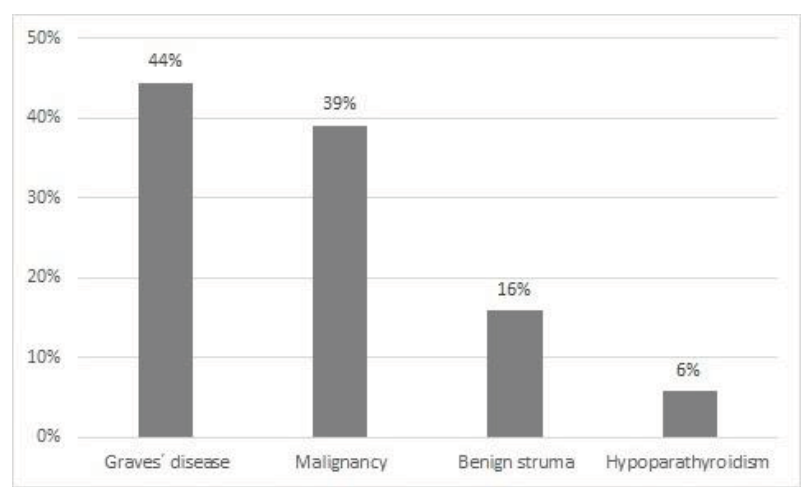

Figure 3 Frequency of dysphagia depending on diagnosis.

Notes: Patients with Graves' disease and carcinomas showed a significantly higher risk and patients with hyperparathyroidism a significantly lower risk of dysphagia. but swallowing disorders appeared de novo or worsened in $20 \%$ of patients. ${ }^{5}$ However, there are also contradictory results regarding dysphagia after thyroid operations. Greenblatt et al report a significant improvement in postoperative swallowing using the standardized SWAL-QOL questionnaire, designed to find out how swallowing problems affect quality of life. ${ }^{2}$ With the same questionnaire, Sabaretnam et $\mathrm{al}^{8}$ reported a significant improvement in quality of life in patients with benign goiters after thyroidectomy and Pinchot et al reported a significant improvement in quality of life in patients with parathyroid disease after thyroidectomy. ${ }^{9}$

Besides these studies specific for postoperative swallowing impairment, there are several further prospective studies with different questionnaires regarding quality of life after thyroid operation. Most studies find that quality of life improves after thyroidectomy, although there are also some contradictory results. ${ }^{10-13}$ Assessment of dysphagia is presumably insufficient in these studies, because the item dysphagia is underrepresented. The often used questionnaire "Thyroid-Related Quality of Life Measure ThyPRO" reports 13 multi-item scales, and dysphagia is only a sub-item of one of the 13 items (goiter symptoms). In the also frequently used SF-36 questionnaire, dysphagia is not included. ${ }^{14}$ All these quality of life studies excluded patients with carcinoma. We found that patients in this group are at high risk of dysphagia, since bilateral thyroid surgery is performed in these patients, often with lymph node dissection. Also at high risk of dysphagia are patients with Graves' disease. In literature, we found no comparable study regarding Graves' disease, although Cramon et al report that Graves' disease causes severe disease-specific and generic health-related quality of life impairments, and deficits persist after treatment. ${ }^{15}$ One particular aspect of Graves' disease could be inflammation, which can favor postoperative scarring.

Reasons for dysphagia could be, among others, postoperative scarring, modification in the vascular supply, or damage to tiny branches of the recurrent laryngeal nerve going to the cricopharyngeal muscle. ${ }^{6}$ The extent of the operative intervention seems to affect the probability of postoperative dysphagia. We found that particularly after lymph node dissection and surgical treatment for Graves' disease, postoperative dysphagia occurs. Lombardi et al report that the incidence and the severity of dysphagia is significantly reduced in patients who undergo video-assisted surgery compared with conventional surgery. ${ }^{16}$ In most cases, correlations for these swallowing disorders do not translate into objective findings and a discordance between objective deterioration and subjective symptoms is reported. ${ }^{6}$ Altered 
objective test results were reported by Scerrino et al. They found a decreased pressure in the upper esophageal sphincter in postoperative esophageal manometry by an average of $25 \%$ after uncomplicated thyroidectomy, recovering to original values after 2 years. ${ }^{5,17}$ In case of radical central neck dissection, the inferior laryngeal nerve and the nerve branches destined for esophageal region are dissected; an extended dissection of the nerves could predispose to risk.

Intubation is also in discussion as a cause of dysphagia, ${ }^{18,19}$ but Pereira et al report that, after comparing prevalence of dysphagia in patients after cholecystectomy and thyroidectomy, long-term symptoms are not related to orotracheal intubation. ${ }^{4}$

Compared to other studies concerning postoperative dysphagia, we included a large collective of patients and analyzed, in contrast to other studies, frequency of dysphagia according to patients' diagnoses. However, our study also has several limitations. This study is retrospective, which means no preoperative swallowing disorders were raised and the duration of the postoperative survey was not uniform. Further, we provided a specifically designed questionnaire, which, with simple questions, covered the spectrum of symptoms typically reported by affected patients. We did not use a well-validated method or the swallowing quality of life validated outcomes assessment tool. ${ }^{2}$ Our questionnaire was not validated in the general population or in other studies. This could be a major limitation. Furthermore, we asked the patients only about subjective symptoms of difficulties in swallowing. We did not detect objectively measurable alterations in these patients. Apart from that, dysphagia is common especially in elderly patients. Approximately $15 \%$ of subjects 65 years and older reported difficulties with swallowing. ${ }^{20}$ These patients were not excluded.

Summarizing, we have shown that patients frequently report postoperative dysphagia after uncomplicated thyroidectomy and parathyroidectomy, especially after major surgical intervention. We found a significant risk of postoperative dysphagia in patients with Graves' disease and carcinoma and a decreased risk for patients operated on for hyperparathyroidism.

\section{Disclosure}

The authors report no conflicts of interest in this work.

\section{References}

1. Trippe BS, Shaprio JR, Doppman JL. Dysphagia. Initial symptom of an ectopic hyperfunctioning parathyroid adenoma. JAMA. 1976;235(1):58-59.
2. Greenblatt DY, Sippel R, Leverson G, Frydman J, Schaefer S, Chen $\mathrm{H}$. Thyroid resection improves perception of swallowing function in patients with thyroid disease. World J Surg. 2009;33(2):255-260.

3. Rosato L, Avenia N, Bernante P, et al. Complications of thyroid surgery: analysis of a multicentric study on 14,934 patients operated on in Italy over 5 years. World J Surg. 2004;28(3):271-276.

4. Pereira JA, Girvent M, Sancho JJ, Parada C, Sitges-Serra A. Prevalence of long-term upper aerodigestive symptoms after uncomplicated bilateral thyroidectomy. Surgery. 2003;133(3):318-322.

5. Scerrino G, Inviati A, di Giovanni S, et al. Esophageal motility changes after thyroidectomy; possible associations with postoperative voice and swallowing disorders: preliminary results. Otolaryngol Head Neck Surg. 2013;148(6):926-932.

6. Lombardi CP, Raffaelli M, D'Alatri L, et al. Voice and swallowing changes after thyroidectomy in patients without inferior laryngeal nerve injuries. Surgery. 2006;140(6):1026-1034.

7. Grover G, Sadler GP, Mihai R. Morbidity after thyroid surgery: patient perspective. Laryngoscope. 2013;123(9):2319-2323.

8. Sabaretnam M, Mishra A, Chand G, et al. Assessment of swallowing function impairment in patients with benign goiters and impact of thyroidectomy: a case control study. World J Surg. 2012;36(6): 1293-1299.

9. Pinchot SN, Youngwirth L, Rajamanickam V, Schaefer S, Sippel R, Chen H. Changes in swallowing-related quality of life after parathyroidectomy for hyperparathyroidism: a prospective cohort study. Oncologist. 2012;17(10):1271-1276.

10. Sorensen JR, Watt T, Cramon P, et al. Quality of life after thyroidectomy in patients with nontoxic nodular goiter: A prospective cohort study. Head Neck. 2017;39(11):2232-2240.

11. Bukvić B, Živaljević V, Šipetić S, Diklić A, Taušanović K, Paunović I. Validation and cross-cultural adaptation of the questionnaire ThyPRO in thyroid patients in Serbia. Vojnosanit Pregl. 2015;72(7):583-588.

12. Promberger R, Hermann M, Pallikunnel SJ, Seemann R, Meusel M, Ott J. Quality of life after thyroid surgery in women with benign euthyroid goiter: influencing factors including Hashimoto's thyroiditis. Am J Surg. 2014;207(6):974-979.

13. Schmitz-Winnenthal FH, Schimmack S, Lawrence B, et al. Quality of life is not influenced by the extent of surgery in patients with benign goiter. Langenbecks Arch Surg. 2011;396(8):1157-1163.

14. Brazier JE, Harper R, Jones NM, et al. Validating the SF-36 health survey questionnaire: new outcome measure for primary care. $B M J$. 1992;305(6846):160-164.

15. Cramon P, Winther KH, Watt T, et al. Quality-of-life impairments persist six months after treatment of graves' hyperthyroidism and toxic nodular goiter: A prospective cohort study. Thyroid. 2016;26(8):1010-1018.

16. Lombardi CP, Raffaelli M, D'Alatri L, et al. Video-assisted thyroidectomy significantly reduces the risk of early postthyroidectomy voice and swallowing symptoms. World J Surg. 2008;32(5):693-700.

17. Scerrino G, Inviati A, di Giovanni S, et al. Long-term esophageal motility changes after thyroidectomy: associations with aerodigestive disorders. G Chir. 2017;37(5):193-199.

18. Chun BJ, Bae JS, Lee SH, Joo J, Kim ES, Sun DI. A prospective randomized controlled trial of the laryngeal mask airway versus the endotracheal intubation in the thyroid surgery: evaluation of postoperative voice, and laryngopharyngeal symptom. World J Surg. 2015;39(7):1713-1720.

19. Ryu JH, Yom CK, Park DJ, et al. Prospective randomized controlled trial on the use of flexible reinforced laryngeal mask airway (LMA) during total thyroidectomy: effects on postoperative laryngopharyngeal symptoms. World J Surg. 2014;38(2):378-384.

20. Chen PH, Golub JS, Hapner ER, Johns MM. Prevalence of perceived dysphagia and quality-of-life impairment in a geriatric population. Dysphagia. 2009;24(1):1-6. 


\section{Publish your work in this journal}

Pragmatic and Observational Research is an international, peer-reviewed, open access journal that publishes data from studies designed to reflect more closely medical interventions in real-world clinical practice compared with classical randomized controlled trials (RCTs). The manuscript management system is completely online and includes a very quick and fair peer-review system. Visit http://www.dovepress.com/testimonials.php to read real quotes from published authors.

Submit your manuscript here: https://www.dovepress.com/pragmatic-and-observational-research-journal 